\title{
REPRESENTASI SISWA SMA DALAM MEMECAHKAN MASALAH MATEMATIKA BERDASARKAN GAYA KOGNITIF
}

\author{
Ika Santia \\ Program Studi Pendidikan Matematika FKIP Universitas Nusantara PGRI Kediri \\ Email: santiaika@ymail.com
}

\begin{abstract}
Abstrak
Salah satu yang menjadi alasan kesulitan siswa kurang dapat memecahkan masalah matematika adalah kurangnya ragam representasi yang dimiliki siswa. Oleh karena itu representasi penting dalam suatu pembelajaran matematika. Kurangnya kemampuan representasi siswa terlihat ketika siswa kesulitan menggunakan representasinya untuk memecahkan permasalahan aplikasi turunan fungsi. Adapun perbedaan representasi siswa dalam memecahkan masalah tersebut juga dipengaruhi oleh gaya kognitif siswa tersebut. Untuk itu dilakukan suatu penelitian kualitatif yang bertujuan mendeskripsikan: (1) representasi siswa SMA dengan gaya kognitif Field Dependent dalam memecahkan masalah matematika (2) representasi siswa SMA dengan gaya kognitif Field Independent dalam memecahkan masalah matematika. Pengumpulan data dilakukan dengan pemberian tugas TPMO dan wawancara. Teknik pemeriksaan keabsahan data yang digunakan adalah triangulasi. Subjek penelitian adalah siswa SMA kelas XII sebanyak 2 orang. Hasil penelitian ini menunjukkan bahwa subjek mereprentasikan idenya untuk memecahkan masalah matematika dengan menggunakan langkah pemecahan masalah Polya: (a) memahami masalah (b) membuat rencana penyelesaian (c) melaksanakan rencana dan (d) memeriksa kembali penyelesaian yang telah dilakukan. Adapun representasi subjek dengan gaya kognitif Field Dependent dalam memecahkan masalah matematika adalah dengan cara: memahami informasi dan apa yang ditanyakan dengan membuat gambar, membuat rencana penyelesaian dengan membuat persamaan matematika, memanipulasi persamaan tersebut dan mengecek kembali hasil akhir yang didapatkan dengan mensubstitusi kembali jawaban akhir ke persamaan awal. Sedangkan subjek dengan gaya kognitif Field Independent merepresentasikan idenya untuk memecahkan masalah dengan cara: memahami informasi dan apa yang ditanyakan dengan menuliskan persamaan matematika menggunkan simbol formal, membuat rencana penyelesaian dengan membuat persamaan matematika, memanipulasi persamaan tersebut dan menggunakan cara coba-coba serta tidak melakukan pengecekan kembali hasil akhir yang diperoleh.
\end{abstract}

Kata Kunci: Representasi, Pemecahan Masalah Matematika, Gaya Kognitif

\section{PENDAHULUAN}

Pembelajaran matematika sekolah tersebut memiliki dua fungsi, yaitu mengembangkan

mengkomunikasikan gagasan melalui

model matematika dan membangun 
kecakapan matematika. Oleh karena itu kecakapan menggunakan berbagai simbol, grafik, tabel, diagram dalam merumuskan, menafsirkan, membuat model matematika untuk memperjelas masalah merupakan bagian penting dalam pembelajaran matematika. Goldin (1987) mengemukakan bahwa pengungkapan ide-ide metematika dengan menggunakan berbagai cara seperti: bahasa lisan, bahasa tulis, simbol, gambar, diagram, model, grafik, atau menggunakan anggota fisik dikatakan sebagai representasi ide. NCTM (2000) juga menyatakan bahwa representasi termasuk dalam standar proses. Hal ini dikarenakan representasi merujuk pada proses pembentukan, abstraksi dan pendemonstrasian pengetahuan matematika.

Untuk berfikir tentang ide matematika dalam menyelesaikan masalah, siswa dipengaruhi oleh tampilan soal. Kemudian menggunakan representasi internalnya siswa mengkonstruksi solusi untuk memecahkan masalah tersebut, tapi sayangnya representasi internal sulit diamati secara langsung karena merupakan aktivitas mental siswa dalam pikirannya (minds on) untuk itu diperlukan representasi eksternal untuk mentransformasikan representasi internal yang ada dalam pikiran siswa agar orang lain dapat mengetahui solusi pemecahan masalah yang dipikirkan siswa. Pemecahan masalah sendiri memiliki peran penting dalam pembelajaran matematika, hal ini dinyatakan oleh Schoenfeld yang mengemukakan bahwa "there is a general acceptance of the idea that the primary goal of mathematics instruction should be to have students become competent problem solver" (Schoenfeld, 1992).

Representasi dengan pemecahan masalah memiliki keterkaitan yang erat seperti yang diungkapkan Jones (dalam Setiyo, 2000: 3), “Empirical studies suggest that mathematics problem solving competency depend on ones's ability to think in term of different representational system during problem solving process". Keterkaitan ini terjadi saat siswa mengkonstruksi representasi yang tepat dengan permasalahan untuk memperoleh solusi yang tepat. Jadi dalam melakukan pemecahan masalah, diperlukan kemampuan seseorang untuk memberi pertimbangan terhadap bentuk representasi yang dilibatkan. Hal tersebut menunjukkan bahwa kecakapan seseorang dalam mengubah suatu representasi ke representasi lainnya akan mempengaruhi kecakapannya dalam 
mencari solusi pemecahan masalah. Sehingga suatu masalah yang rumit dapat menjadi sederhana jika menggunakan masalah yang tepat.

Salah satu konsep matematika yang menjadi fokus penelitian dewasa ini adalah nilai optimum suatu fungsi. Villegas, dkk. (2006) meneliti mengenai representasi siswa dalam menyelesaikan masalah nilai optimum fungsi pada siswa The Faculty of Science,University of Granada, Spain tahun angkatan 20012002. Dan hasilnya pada permasalahan nilai optimum suatu fungsi siswa kesulitan memodelkan permasalahan karena kurangnya kemampuan representasi. Kemudian, dengan mengadaptasi soal tes yang digunakan Villegas, dkk. (2006) diadakan observasi tak terstruktur pada kelas XII di salah satu SMA. Permasalahan diberikan pada 36 orang siswa. Adapun permasalahan tersebut tentang mencari nilai optimum suatu fungsi, yaitu: Suppose that we want to construct a rectangle that has perimeter $100 \mathrm{~cm}$. and whose area is as large as possible. Dari 36 siswa tersebut diperoleh respon diantaranya: 15 orang siswa $(41,7 \%)$ menjawab salah dan menggunakan cara trial and error. Mereka mencoba menentukan ukuran persegi panjang tersebut, yaitu $30 \mathrm{~cm}$,
$20 \mathrm{~cm}, 30 \mathrm{~cm}, 20 \mathrm{~cm}$ sehingga luasnya adalah $600 \mathrm{~cm}^{2}$, ada juga beberapa siswa yang mencoba menentukan ukuran lain persegi panjang tersebut, yaitu $35 \mathrm{~cm}$, $15 \mathrm{~cm}, 35 \mathrm{~cm}, 15 \mathrm{~cm}$ yang luasnya adalah $525 \mathrm{~cm}^{2}$ dan lebih kecil dari perkiraan ukuran yang sebelumnya. Siswa-siswa tersebut menggunakan representasi numeric tetapi dalam penyelesaian masalah tersebut masih salah dalam menemukan hasil akhir jawaban permasalahan. Sebanyak 10 orang siswa $(27,8 \%)$ mampu menggunakan representasinya untuk memecahkan masalah tersebut

Masalah matematika yang digunakan dalam penelitian ini adalah soal tentang nilai optimum suatu fungsi yang dapat dipahami siswa serta tidak dapat dengan segera ditemukan cara penyelesaiannya oleh siswa melainkan membutuhkan pemikiran lebih lanjut untuk menyelesaikannya.Sedangkan pemecahan masalah matematika adalah suatu proses yang dilakukan siswa dalam menyelesaikan suatu masalah matematika dengan mengaplikasikan pengetahuan, keterampilan serta pemahaman yang dimiliki. Proses penyelesaian masalah ini meliputi: memahami masalah, merencanakan cara penyelesaian, melaksanakan rencana, dan melakukan 
pengecekan kembali terhadap semua Muzakir (2006), maka dapat disusun langkah yang telah dikerjakan.

Berpedoman pada tahap-tahap indikator representasi siswa dalam penyelesaian masalah yang dikemukakan memecahkan masalah matematika adalah sebagai berikut:

Polya dan indikator representasi menurut

Tabel 1. Indikator Representasi dalam Pemecahan Masalah Nilai optimum suatu fungsi

\begin{tabular}{|l|c|}
\hline \multicolumn{1}{|c|}{ Indikator Representasi } \\
dalam Memecahkan Masalah & Tahap Pemecahan Masalah Polya \\
- Menyajikan kembali data / informasi yang \\
diketahui melalui gambar, teks tulis, kata-kata, \\
atau notasi/simbol formal.
\end{tabular}

Representasi juga erat kaitannya "complexities of representation as a dengan gaya kognitif. Seperti halnya yang cognitive and social process and of how it diungkapkan oleh ( $\mathrm{Wu}, 2004:$ 32) is inextricably linked with the knowledge 
people have the situation being presented." Hal ini berarti representasi sebagai proses kognitif dan berhubungan dengan pengetahuan siswa. Karena representasi merupakan proses kognitif, maka gaya kognitif siswa memberikan pengaruh yang besar dalam pemecahan masalah. Gaya kognitif didefinisikan Messick (dalam Kozhevnikov, 2007) sebagai "Stable attitudes, preferences or habitual strategies that determine individuals model of perceiving, remembering, thinking, and problem solving." Gaya kognitif berdasarkan dimensi psikologi secara konsistensi mewakili kemampuan kognitif seseorang, terutama berhubungan dengan aspek perseptual dan intelektual.

Dalam penelitian ini, peneliti memilih fokus pada tipe gaya kognitif Field Dependent (FI )- Field Independent (FD) yang dikembangkan oleh Witkin (1977) karena berdasarkan beberapa penelitian sebelumnya menunjukkan bahwa karakteristik dari gaya kognitif ini banyak dijumpai pada siswa dalam pembelajaran. Hal ini sesuai dengan yang dikemukakan Tinajero \& Paramo (1998) yang mendapatkan bahwa dari 233 siswa yang menjadi subjek penelitiannya terdapat 189 siswa yang memiliki gaya kognitif $F I-F D$. Gaya kognitif $F D$ adalah suatu gaya kognitif yang dimiliki siswa dengan menerima sesuatu lebih global dan mengalami kesulitan untuk memisahkan diri dari keadaan lingkungannya atau lebih dipengaruhi oleh lingkungannya. Sedangkan FI adalah gaya kognitif yang dimiliki siswa yang cenderung menyatakan suatu gambaran lepas dari latar belakang gambaran tersebut, dan mampu membedakan objekobjek dari konteks sekitarnya. Siswa FI akan bekerja lebih baik jika diberikan kebebasan dan siswa $F D$ akan bekerja lebih baik jika diberikan petunjuk dan arahan. Kedua sifat yang berbeda tersebut akan mempengaruhi representasi yang dipakai siswa tersebut dalam memecahkan masalah, karena dimungkinkan siswa $F D$ akan lebih terpengaruh oleh representasi guru dalam memecahkan masalah.

Instrumen yang digunakan untuk mengukur gaya kognitif $F I$ dan $F D$ adalah The Group Embedded Figure Test (GEFT) yang dikembangkan oleh (Witkin et al., 1977) yang telah teruji validasinya. Tugas subjek penelitian dalam tes ini adalah mempertebal gambar sederhana yang terdapat di dalam gambar-gambar rumit untuk masing-masing soal. Siswa dengan skor dibawah $50 \%$ dari skor maksimal yaitu 9 atau kurang maka siswa 
tersebut digolongkan sebagai siswa field dependent.

Demikian pentingnya representasi ini sehingga seharusnya para guru memberikan perhatian guna mengembangkan ragam representasi siswa dalam memecahkan masalah matematika terutama siswa pada jenjang Sekolah Menengah Atas (SMA). Karena siswa SMA berada pada tahap operasional formal dimana mereka mulai mampu berpikir secara abstrak, menalar secara logis dan menarik kesimpulan dari informasi yang ada (Piaget \& Inhelder dalam Genovese, 2003).

\section{METODE}

\section{Jenis Penelitian}

Jenis penelitian ini adalah penelitian eksploratif dengan pendekatan kualitatif karena setting penelitian berlatar alami dan instrumen utama penelitian adalah peneliti sendiri. Dalam hal ini penelitian ini dimaksudkan untuk mengungkapkan representasi siswa FI$F D$ di SMA dalam memecahkan masalah matematika. Penelitian ini merupakan suatu analisis terhadap hasil pekerjaan subjek penelitian dan wawancara terhadap subjek penelitian.

\section{Subjek Penelitian}

Subjek dalam penelitian ini adalah dua orang siswa SMA yang terdiri dari siswa dengan gaya kognitif FI dan FD yang berkemampuan dasar deferensial setara dan dapat berkomunikasi dengan lancar.

Pemilihan subjek dilakukan dengan memberikan tes gaya kognitif. Dalam satu kelas diberikan tes gaya kognitif kemudian siswa dikelompokkan menjadi dua kelompok, yaitu kelompok FI dan $F D$. Kemudian siswa diberikan tes dasar diferensial dan dicari siswa yang memiliki selisih nilai tes deferensial kurang dari samadengan 5\% dari skor total untuk didapatkan siswa yang memilki kemampuan setara.

Setelah kedua kelompok tersebut terisi siswa dengan gaya kognitif $F I$ dan $F D$ serta berkemampuan deferensial setara, dipilih salah satu siswa dari masingmasing kelompok yang dapat berkomunikasi dengan lancar serta bersedia untuk diwawancarai. Dengan demikian untuk mendapatkan subjek penelitian maka peneliti perlu berkoordinasi dengan guru matematika yang mengajar di kelas yang bersangkutan.

\section{Teknik Pengumpulan Data}

Pengumpulan data dalam penelitian ini akan dilakukan dengan dua teknik yaitu tes tertulis dan wawancara. Proses 
pengumpulan data tes tertulis diperoleh dari hasil tes pada tes gaya kognitif dan soal Tes Pemecahan Masalah Optimum Fungsi (TPMO). Pengumpulan data diawali dengan pemberian tes gaya kognitif dan tes kemampuan dasar deferensial. Kemudian data tentang gaya kognitif yang diperoleh digunakan untuk menentukan subjek penelitian. Proses berikutnya, subjek diberikan soal Tes Pemecahan Masalah Optimum Fungsi (TPMO) dan dilakukan wawancara terhadap subjek berdasarkan hasil pekerjaan TPMO. Untuk menjamin keabsahan data dalam penelitian ini akan dilakukan triangulasi. Data dikatakan valid jika ada konsistensi atau kesamaan pandangan antara data pertama dan data kedua. Jika data yang diperoleh belum valid, maka dilakukan pengumpulan data berulang kali sampai data yang diperoleh valid.

\section{Teknik Analisis Data}

Proses analisis data dilakukan mengikuti langkah- langkah berikut: (1) Mereduksi data yang terdiri dari membuat ringkasan yang terorganisir terhadap seluruh data yang diperoleh pada tes gaya kognitif; Memeriksa dan menelaah hasil TPMO kemudian membuat transkrip data yang terdiri dari penjelasan siswa terhadap pada soal masalah yang diberikan dalam bentuk tertulis; Menelaah hasil rekaman wawancara

kemudian membuat transkrip hasil wawancara, dilakukan penyeleksian data terhadap ttranskrip-transkrip yang dibuat dengan membuang data yang tidak relevan, membuat ringkasan yang terorganisir, dan menggolongkan dalam satu pola yang lebih luas. Dalam proses ini, analisis tentang representasi siswa sudah dapat dilakukan, (2) Penyajian data yang dibuat dengan tersusun rapi dan terorganisir serta (3) Penarikan kesimpulan yang didasarkan pada hasil analisis terhadap data yang telah terkumpul dengan membandingkan kesesuaian pernyataan subjek dengan makna yang terkandung dalam pertanyaan penelitian yang diteliti untuk mendeskripsikan representasi siswa dalam memecahkan masalah nilai optimum suatu fungsi berdasarkan gaya kognitif FI-FD.

\section{Prosedur Penelitian}

Secara garis besar, langkah-langkah dalam penelitian ini meliputi kegiatan sebagai berikut: (1) Kegiatan awal yakni dengan mengkaji teori tentang pengaturan diri untuk selanjutnya membuat laporan dan menyusun draft instrumen, (2) Kegiatan inti yang dilakukan dengan pemberian tes gaya kognitif untuk 
memilih subjek yang diinginkan untuk selanjutnya diberikan tugas

TPMO dan wawancara serta (3) Kegiatan akhir yang meliputi pengolahan dan analisis data sehingga dapat merumuskan representasi siswa dalam memecahkan masalah nilai optimum suatu fungsi berdasarkan gaya kognitif FI-FD untuk menyusun laporan penelitian dan penyimpulan akhir.

\section{HASIL DAN PEMBAHASAN}

Selama proses menyelesaikan masalah nilai optimum fungsi yang diberikan terdapat beberapa perbedaan representasi yang dilakukan oleh subjek dengan gaya kognitif FI-FD. Perbedaan tersebut terlihat pada tabel di berikut ini:

Tabel 2. Ringkasan Representasi Siswa SMA dalam Memecahkan Masalah Nilai optimum Suatu Fungsi Berdasarkan Gaya Kognitif

\begin{tabular}{|c|c|c|}
\hline \multirow{2}{*}{$\begin{array}{c}\text { Langkah } \\
\text { Pemecahan } \\
\text { Masalah Polya }\end{array}$} & \multicolumn{2}{|c|}{ Deskripsi Representasi } \\
\hline & Field-Dependent & Field-Independent \\
\hline $\begin{array}{l}\text { Memahami } \\
\text { Masalah }\end{array}$ & 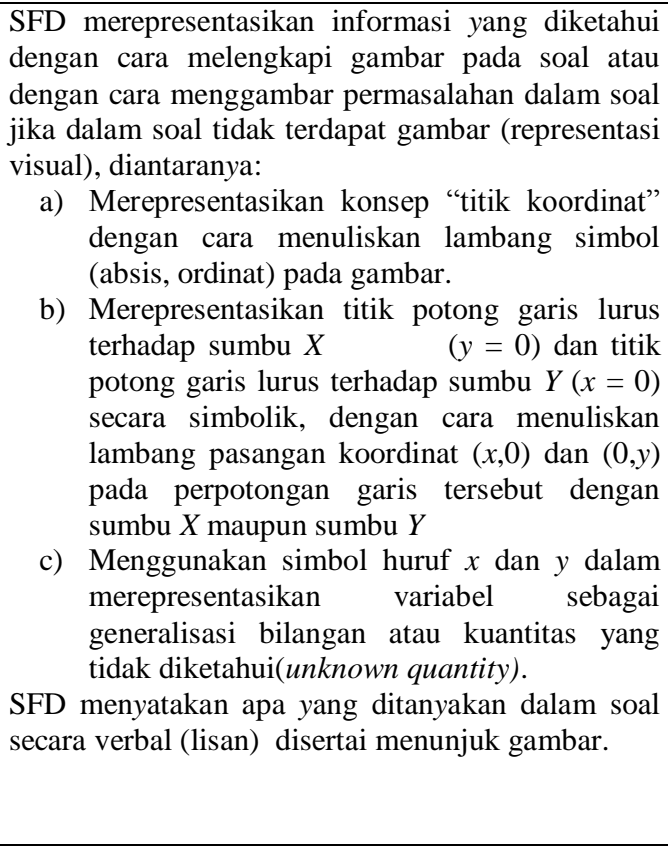 & $\begin{array}{l}\text { SFI merepresentasikan informasi yang } \\
\text { diketahui dalam soal dengan cara membaca } \\
\text { dan melihat kalimat pada soal kemudian } \\
\text { menulis informasi yang diketahui dengan } \\
\text { menggunakan simbol formal. Diantaranya : } \\
\text { a) Menuliskan suatu persamaan linier } \\
a x+b y=a b \text { dan merubahnya } \\
\text { menjadi fungsi linier } y=a-\frac{a}{b} x \\
\text { b) Merepresentasikan konsep "range } \\
\text { fungsi" dengan } \\
f(a)=3-\frac{1}{2} a \\
\text { c) Tidak selalu menggunakan simbol } \\
\text { huruf } x \text { dan } y \text { dalam merepresentasikan } \\
\text { variabel sebagai generalisasi bilangan } \\
\text { atau kuantitas yang tidak } \\
\text { diketahui(unknown quantity). }\end{array}$ \\
\hline $\begin{array}{c}\text { Membuat } \\
\text { Rencana } \\
\text { Penyelesaian } \\
\text { Masalah }\end{array}$ & $\begin{array}{l}\text { SFD menyatakan secara tertulis langkah-langkah } \\
\text { rencana yang akan digunakan untuk memecahkan } \\
\text { masalah. Diantaranya: } \\
\text { a) Menuliskan cara memperoleh persamaan } \\
\text { garis } \\
\text { b) Menuliskan cara memperoleh persamaan luas } \\
\text { dengan mensubstitusi persamaan garis yang } \\
\text { telah ditentukan. } \\
\text { Menuliskan model matematika atau persamaan }\end{array}$ & $\begin{array}{l}\text { SFI menyatakan secara tertulis langkah- } \\
\text { langkah rencana yang akan digunakan untuk } \\
\text { memecahkan masalah menggunakan } \\
\text { notasi/simbol formal secara tertulis. Langkah } \\
\text { yang diambil yaitu menentukan persamaan } \\
\text { luas, kemudian mencari nilai maksimalnya } \\
\text { dengan turunan pertama sama dengan nol. } \\
\text { Menuliskan model matematika atau }\end{array}$ \\
\hline
\end{tabular}




\begin{tabular}{|c|c|c|}
\hline & $\begin{array}{l}\text { matematika dengan representasi simbol formal atau } \\
\text { ekspresi matematika yaitu persamaan garis dan } \\
\text { persamaan luas. }\end{array}$ & $\begin{array}{l}\text { persamaan matematika dengan representasi } \\
\text { simbol formal yaitu persamaan luas }\end{array}$ \\
\hline $\begin{array}{c}\text { Melaksanakan } \\
\text { Rencana } \\
\text { Penyelesaian } \\
\text { Masalah }\end{array}$ & $\begin{array}{l}\text { Memanipulasi model matematika yang telah dibuat } \\
\text { dalam melaksanakan rencana penyelesaian } \\
\text { masalah. } \\
\text { a) Menuliskan turunan fungsi } L \text { yaitu } L \text {, } \\
\text { dengan memanipulasi fungsi } L \text { yang telah } \\
\text { dimodelkan } \\
\text { b) Menuliskan cara memperoleh nilai luas } \\
\text { maksimum persegi panjang yang dicari } \\
\text { dengan mensubstitusikan nilai } x \text { yang } \\
\text { didapatkan ke persamaan luas } \\
\text { SFD mengaitkan rencana pemecahan masalah yang } \\
\text { telah dibuat dengan suatu konsep titik stasioner } \\
\text { dengan menuliskan } L,=0\end{array}$ & $\begin{array}{l}\text { SFI menggunakan ekspresi dan } \begin{array}{r}\text { simbol } \\
\text { model }\end{array} \\
\text { matematika dalam membuat } \\
\text { matematika dalam melaksanakan rencana } \\
\text { penyelesaian masalah. Diantaranya: } \\
\text { a) SFI menuliskan turunan fungsi } L \\
\text { dengan memanipulasi persamaan luas } \\
\text { yang telah dimodelkan. } \\
\text { b) SFI menuliskan cara memperoleh nilai } \\
\text { luas maksimum yang dicari dengan } \\
\text { mensubstitusikan nilai a dan b yang } \\
\text { didapatkan sehingga didapatkan luas } \\
\text { maksimum. } \\
\text { SFI juga menyatakan secara verbal (lisan) } \\
\text { hubungan luas maksimum dengan konsep } \\
\text { titik balik maksimum }\end{array}$ \\
\hline $\begin{array}{l}\text { Mengecek } \\
\text { Kembali }\end{array}$ & $\begin{array}{l}\text { Merepresentasikan simbol/notasi yang digunakan } \\
\text { serta mengintepretasikan hasil jawaban dari } \\
\text { simbol formal ke bahasa lisan (dalam kata-kata) } \\
\text { - Melakukan pemeriksaan ulang langkah } \\
\text { penyelesaian yang telah dilakukan adalah dengan } \\
\text { cara mensubstitusikan kembali jawaban akhir ke } \\
\text { persamaan awal. } \\
\text { - SFD tidak menjelaskan secara tertulis apakah } \\
\text { jawaban yang diperoleh telah menjawab } \\
\text { pemasalahan yang diberikan. }\end{array}$ & $\begin{array}{l}\text { - Merepresentasikan simbol/notasi yang } \\
\text { digunakan serta mengintepretasikan hasil } \\
\text { jawaban dari simbol formal ke bahasa lisan } \\
\text { (dalam kata-kata). } \\
\text { - Tidak melakukan pemeriksaan ulang } \\
\text { langkah penyelesaian yang telah dilakukan. } \\
\text { - SFD tidak menjelaskan secara tertulis } \\
\text { apakah jawaban yang diperoleh telah } \\
\text { menjawab pemasalahan yang diberikan }\end{array}$ \\
\hline
\end{tabular}

\section{KESIMPULAN DAN SARAN}

\section{Kesimpulan}

Berdasarkan hasil analisis dan pembahasan data penelitian yang telah diuraikan, peneliti dapat menyimpulkan bahwa:

1. Representasi siswa SMA dengan gaya kognitif field dependent dalam memecahkan masalah matematika dapat dijelaskan sebagai berikut.

a. Tahap Memahami Masalah

$\begin{array}{lcr}\begin{array}{l}\text { Representasi } \\ \text { dependent }\end{array} & \text { subjek } & \text { field } \\ \text { memahami } & \text { masalah } & \text { dalam } \\ \text { melengkapi } & \text { adalah } \\ \text { mar pada soal dan }\end{array}$

membuat gambar tentang permasalahan dalam soal. Kemudian menuliskan lambang tanda noktah pasangan koordinat ( $\left.x_{1}, 0\right) \quad$ dan $\left(0, y_{1}\right)$ pada perpotongan garis dengan sumbu $X$ maupun sumbu $Y$. SFD juga menuliskan lambang koordinat $(x, y)$ pada titik sudut persegipanjang yang dilalui garis. SFD tidak menuliskan apa yang diketahui dan apa yang ditanyakan. Sehingga bentuk representasi SFD diwujudkan dalam bentuk tertulis (gambar dan simbol matematika). 
b. Tahap Merencanakan Penyelesaian Masalah

Representasi

SFD dalam

merencanakan penyelesaian

masalah dilakukan secara tertulis.

SFD menuliskan persamaan garis

dan rumus luas persegi panjang

serta luas segitiga, kemudian

menyatakan secara lisan bahwa

langkah selanjutnya adalah

mensubstitusi persamaan garis ke

persamaan luas. Bentuk

representasi SFD diwujudkan

secara tertulis (persamaan

matematika) dan verbal ( kata-kata

secara lisan).

c. Tahap Melaksanakan Rencana

Penyelesaian Masalah

SFD manipulasi model matematika yang telah dibuat saat merencana penyelesaian masalah. Diantaranya merepresentasikan turunan fungsi luas dengan menuliskan simbol $L^{\prime}$ dengan memanipulasi fungsi $L$ yang telah dimodelkan, merepresentasikan persamaan linier sebagai garis lurus yang memiliki gradien dan melalui sebuah titik $\left(x_{1}, y_{1}\right)$ dengan menuliskan rumus $y-y_{1}=m\left(x-x_{1}\right)$. SFD mengaitkan rencana pemecahan masalah yang telah dibuat dengan suatu konsep titik stasioner dengan menuliskan $L^{\prime}=$ 0 . Sehingga bentuk representasi SFD pada tahap melaksanakan rencana penyelesaian masalah diwujudkan secara tertulis (persamaan matematika dan simbol matematika).

d. Tahap Memeriksa Kembali Penyelesaian

Subjek field dependent mengintepretasikan hasil jawaban dari simbol formal ke bahasa lisan (dalam kata-kata) untuk menyatakan jawaban akhir dari masalah tersebut. SFD merepresentasikan ide-idenya secara lisan bahwa yang dilakukan untuk memeriksa ulang langkah penyelesaian yang telah dilakukan adalah dengan cara mensubstitusikan kembali jawaban akhir ke persamaan awal. Sehingga bentuk representasi SFD pada tahap ini adalah simbol matematika dan verbal (kata-kata secara lisan).

Berdasarkan kesimpulan di atas, didapatkan gambaran bahwa subjek dengan gaya kognitif field dependent sangat bergantung pada gambar dalam pemecahan masalah. Subjek membuat 
persamaan matematika dan memanipulasinya. Serta mengintepretasikan hasil jawaban dari simbol formal ke bahasa lisan (representasi verbal). Subjek field dependent merepresentasikan idenya secara lisan (dengan kata-kata) bahwa yang akan dilakukan pada tahap memeriksa kembali adalah dengan cara mensubstitusikan kembali jawaban akhir ke persamaan awal. Sehingga tampilan ide matematika siswa yang ditampilkan dalam bentuk; gambar, simbol dan ekspresi matematika sertan verbal ( kata-kata secara lisan).

2. Representasi siswa SMA dengan gaya kognitif field independent dalam memecahkan masalah matematika dapat dijelaskan sebagai berikut.

a. Tahap Memahami Masalah

Subjek field independent (SFI) merepresentasikan informasi yang diketahui dalam soal dengan cara membaca kalimat pada soal kemudian menulis persamaan matematika, panjang dan lebar persegi panjang, alas dan tinggi segitiga secara tertulis dengan tepat. SFI tidak membuat gambar ataupun melengkapi gambar yang terdapat pada soal. Menuliskan suatu persamaan linier $a x+b y=a b$ dan merubahnya menjadi fungsi linier $y=a-\frac{a}{b} x$ Pada lembar pekerjaan, SFI cenderung tidak menuliskan apa yang diketahui dan apa yang ditanyakan. Sehingga bentuk representasi SFI diwujudkan secara tertulis (persamaan matematika).

b. Tahap Merencanakan Penyelesaian Masalah

Representasi SFI saat merencanakan penyelesaian masalah adalah dengan menuliskan persamaan garis dan rumus luas persegi panjang serta luas segitiga dengan tepat, kemudian menyatakan secara lisan bahwa langkah selanjutnya adalah mencari nilai maksimalnya dengan turunan pertama sama dengan nol. SFI menyatakan secara lisan cara penyelesaian lain yaitu dengan cara "coba-coba" untuk mensubstitusi pasangan bilangan yang mewakili unsur-unsur luas dan mensubstitusikannya ke dalam rumus luas agar didapatkan luas maksimum. Sehingga bentuk representasi SFI diwujudkan secara tertulis (persamaan matematika) dan lisan. 
c. Tahap Melaksanakan Rencana Penyelesaian Masalah

SFI mengikuti rencana yang telah tersusun sebelumnya. SFI menggunakan konsep titik stasioner dan mengalami kemacetan, sehingga subjek menggunakan alternatif cara penyelesaian lainnya yaitu menggunakan cara "coba-coba". SFI merepresentasikan simbol yang beragam melalui variabel dalam persamaan matematika yang dibuat, seperti ketika subjek field independent merepresentasikan konsep range fungsi dengan simbol $f(a)$. Dalam tahap ini, subjek merepresentasikan ide-idenya secara tertulis (persamaan matematika).

d. Tahap Memeriksa Kembali Penyelesaian

Subjek field dependent tidak melakukan representasi pada tahap ini.

Berdasarkan simpulan di atas, didapatkan gambaran bahwa subjek dengan gaya kognitif field independent diantaranya adalah tidak selalu menggunakan gambar dan memiliki ragam representasi simbol yang cukup baik. Subjek field independent cenderung merepresentasikan ide-idenya melalui simbol-simbol matematika. Tetapi subjek field independent tidak melakukan representasi pada tahap memeriksa kembali pelaksanaan rencana penyelesaian masalah yang telah dibuat.

\section{Saran}

Berdasarkan simpulan hasil penelitian ini, dapat peneliti kemukakan saran sebagai berikut:

1. Guru diharapkan memperhatikan gaya kognitif field dependent dan field independent saat membuat soal karena kedua gaya kognitif tersebut berpengaruh pada ragam representasi siswa dalam menyelesaikan masalah.

2. Subjek field dependentselalu merepresentasikan permasalahan dengan cara yang sama yaitu menggambar, oleh karena itu guru diharapkan dapat memberikan bantuan dan penguatan yang lebih banyak untuk siswa field dependent agar dapat mengembangkan ragam representasi yang dimiliki, khususnya dalam menyelesaikan masalah.

3. Siswa field independent menggunakan simbol-simbol formal yang beragam dalam menyelesaikan masalah. Oleh karena itu disarankan kepada guru agar memberikan tugas 
menyelesaikan masalah yang lebih melibatkan ragam representasi siswa.

\section{DAFTAR PUSTAKA}

Arikunto, Suharsimi. 1996. Dasar-dasar

$\begin{array}{lll}\text { Evaluasi } & \text { Pendidikan } & \text { (Edisi } \\ \text { Revisi). } & \text { Bandung: } & \text { Bumi } \\ \text { aksara. } & & \end{array}$

Code, Jillianne and Zaparyniuk,

Nicholas. 2006. "Individual

Differences in Self-Regulated

Learning: The Role of Cognitive

Style in Adaptive e-Learning. In

E. Pearson \& P. Bohman (Eds.)".

Proceedings of World

Conference on Educational

Multimedia, Hypermedia and

Telecommunications 2006 (pp.

2673-2678). Chesapeake, VA:

AACE.

http://editlib.org/noaccess/23385.

Diakses pada tanggal 3 Maret 2013

Depdiknas. 2006. Peraturan Menteri No

23 Tahun 2006 Tentang Standar

Kompotensi Kelulusan. Jakarta:

Depdiknas.

Ellermeyer S. F. 2001. Using Derivatives

in Problem Solving. Europe Mathematics Journal. Diakses pada 24 November 2012.
Gagantis, Athanasios. A Review of The Research on The role of External Representation on Understanding and Learning Mathematics and Problem Solving.

Gagantis, A \& Elia, I. 2005. A Review of Some Recent Studies On The

Role of Representations in Mathematics Education In Cyprus and Greece.

[Online].Tersedia: http://cerme4.crm.es/Papers\%20d efinitius/1/gagatsis.pdf.

Goldin, Gerald A. \& Kaput, James J. 2004. A Join Perspective on The Idea of Representation in Learning and Doing Mathematics. Rutger University Guisande, Adelina M. 2007. Field Dependence-Independence (FDI) Cognitive Style: An Analysis of Attentional Functioning. Universidad de Oviedo espana. http://www.redalyc.org/articulo.o $\underline{\mathrm{a} ? \mathrm{id}=72719405}$

Harries, T. \& Barmby, P. 2006. Representing Multiplication. Proceeding of the British Society for Research into Learning Mathematics. 26(3), 25 - 30. 
Hiebert, J., dan Carpenter, T. 2000.

Making Sense: Teaching and

Learning Mathematics with

Understanding. Ch-01.

Hudojo, Herman. 1988. Mengajar

Belajar Matematika. Jakarta:

Depdikbud, LPTK.

Jones, A.D. (2000). The Fifth Process

Standart: An Argument to

Include Representation in

Standards 2000. University of

Maryland.

http://www.math.umd.edu/ dac/6

50/jonespaper.html Diakses

tanggal 10 Maret 2013.

Jones dan Knut. 2005. Multiple

Representation Skill and

Creativity Effects On Mathematics

Problem Solving Using A

Multimedia Whiteboard System

Educational Technology dan

Society. National Central

University. Taiwan.

Jung, Inchul. 2002. Student

Representation and

Understanding of Geometric

Transformation with Technology

Experience.

Doctorial

Dissertation, The University of Georgia.

http://jwilson.coe.uga.edu/pers/ju ng_inchul_200205_phd.pdf.

Diakses pada 30 Januari 2013

Kaput, J. 1987. Representation System and Mathematics: Problem of Representations In Mathematics Learning and Problem Solving. Hillsdale, NJ: Lawrence Erlbaum Associates.

Kartini. 2009. "Peranan Representasi

Dalam Pembelajaran

Matematika". Makalah disajikan pada Seminar Matematika dan Pendidikan Matematika di FMIPA UNY, Yogyakarta.

Kozhevnikov, Maria. 2007. Cognitive Style in The Context of Modern Psychology: Toward an Integrated Framework of Cognitive Style. American Psycological Association Journal, Vol. 133, No. 3, 464-481. Diakses pada 25 Januari 2013

Lesh, R. and Landau, M. 1983. Acquisition of Mathematics Concepts And Processes. Illionis: School of Education Northwestern University Evanston.

Luitel, B. C. 2001. Multiple Representations of Mathematical Learning.

http://www.matedu.cinvestav.mx 
ladalira.pdf. Diakses 9 Maret 2013.

Moleong, L. 2007. Metodologi Penelitian

Kualitatif. Edisi Revisi. Bandung:

Remaja Rosdakarya Offset.

Mudzakir. 2006. Representasi Belajar

Berbasis Masalah. Jurnal

Matematika

atau

Pembelajarannya..

ISSN:085-

7792. Tahun viii, edisi khusus.

National Council of Teachers of

Mathematics. (1989), Curriculum

and Evaluation Standards for

School Mathematics, Reston,

Virginia: NCTM.

National Council of Teachers of

Mathematics. (2000), Curriculum

and Evaluation Standards for

School Mathematics, Reston,

Virginia: NCTM.

Panjaitan, Binur. 2012. Pemecahan Masalah Matematika

Berdasarkan Gaya Kognitif.

Disertasi Disertasi doktor,

Universitas Negeri Surabaya.

Pehkonen, Erkki. 2011. Problem Solving

In Mathematics Education In

Finland. Finland: University of Helsinki.

Polya, G. 1973. How to Solve It. A New

Aspect of Mathematics. New
Edition. New Jersey. Princeton:

Princeton University Press.

Radford, L. 2001. Rethinking

Representations. [Online].

Tersedia:

http://www.matedu.cinvestav.mx

/Radford.pdf

Rosengrant, D, et.al (2005). An

Overview of Recent Research on

Multiple Representations.

[Online]. Tersedia:

http://paer.rutgers.edu/Scientific

Abilities/Downloads/Papers/Davi

dRosperc2006.pdf

Santrock, John W. (2004). Educational

Psychology, 2nd Edition. Dallas:

McGraw-Hill Company, Inc.

Schoenfeld, A. H. (1992). Learning to think mathematically: Problem solving, metacognition, and sense-making in mathematics. In D. Grouws (Ed.), Handbook for Research on Mathematics Teaching and Learning (pp. 334370). New York: MacMillan.

Setiyo, Edy. 2013. Profil Representasi Eksternal Siswa Tuna Grahita Ringan Dalam Pemecahan Masalah Persegi dan Persegi Panjang. Tesis Magister Pendidikan, Universitas Negeri Surabaya. 
Siswono, T.Y.E. 2010. Penelitian

Pendidikan

Matematika.

Surabaya: Unesa University Press.

Sudarsono. 2011. Proses Berpikir Siswa

Dalam Mengkonstruksi Koneksi

Matematika Melalui Pemecahan

Masalah. Tesis Magister

Pendidikan, Universitas Negeri

Surabaya.

Sugiyono. (2005). Memahami Penelitian

Kualitatif. Bandung: Alfabeta.

Suherman, Erman. 2001. Strategi

Pembelajaran Matematika

Kontemporer. Bandung: JICA-

UPI

Sumarmo, U. 1994. Suatu Alternatif

Pengajaran Untuk Meningkatkan

Kemampuan Problem Solving

Matematika Pada Guru dan

Siswa SMP. Laporan Hasil

Penelitian. Bandung: Tidak

Diterbitkan.

Susanto, H. A. 2011. Pemahaman

Mahasiswa dalam Pemecahan

Masalah Pembuktian pada

Konsep grup Berdasarkan Gaya

Kognitif. Disertasi doktor,

Universitas Negeri Surabaya.

Tinajaro, C. and Paramo, F. 1998. Field

Dependence-Independence in

Second-Language Acquisition:
Some Forgotten Aspect.

University of Santiago.

Undang-Undang Republik Indonesia

Nomor 20 Tahun 2003 Tentang

Sistem Pendidikan Nasional. 2009.

Bandung: Citra Umbara.

Verschaffel, Lieven et.al,. 2010. Use of Representations in Reasoning and Problem Solving. Routledge:

Taylor dan Francis Group.

Villegas, J. Castro, E. \& Guiterrez, J. 2006. Representation in Problem Solving: A Case Study With Optimization Problems. Spain: The Faculty of Science,University of Granada.

Warsitasari, Wahyu Dwi. 2013. Profil Berpikir Aljabar Siswa SMP dalam Pemecahan Masalah Matematika Ditinjau

Tingkat Kemampuan. Tesis Magister Pendidikan, Universitas Negeri Surabaya.

Wilson, Patricia S. 1993. Research Ideas for The Classroom High School Mathematics. National Council of Teachers of Mathematics Research Interpretation Project, Macmillan Publishing Company.

Wu, Zonghe. 2004. The Study of Middle School Teacher's Understanding 


and Use Mathematical
Representation In Relation To
Teacher's Zone Proximal
$\begin{aligned} & \text { Developement in } \\ & \text { Fractions and Algebraic }\end{aligned}$
Functions. Disertation Doctor of
Philosophy, Texas AdanM
University.

Yoon, S-Y., dan D'Souza, N. 2009.

Different Visual Cognitive Styles,

Different Problem Solving Styles.

Seoul, Korea: International

association of Sociaties of

Design Research.

Zhang, Jiajie. External representation

In Complex Information

Processing Task. Department

of Health Informatics

University of Texas.

http://acad88.sahs.uth.tmc.edu.

Diakses tanggal 30 Maret

2013. 